\title{
Fetal HDlive Silhouette Mode in Clinical Practice
}

\author{
${ }^{1}$ Mohamed Ahmed Mostafa AboEllail, ${ }^{2}$ Kenji Kanenishi, ${ }^{3}$ Genzo Marumo \\ ${ }^{4}$ Hiroshi Masaoka, ${ }^{5}$ Akira Ejiri, ${ }^{6}$ Toshiyuki Hata
}

\begin{abstract}
Many rendering modes and types of software have been introduced as tools to aid in the prenatal detection of fetal anomalies. They aim at facilitating the diagnosis, increasing physicians' confidence, and achieving a better understanding of these anomalies. The HDlive silhouette mode is a novel technology, which provides vitreous-like clarity of the fetus and placenta. Through using a shadowing effect, the outlines of structures of interest can be delineated clearly with a simultaneous display of the inner core and structure. It is more beneficial for identifying a normal anatomy and diagnosing complex congenital malformations. Moreover, the shadowing effect allows the operator to observe structures present behind the directly visualized structure, making it more advantageous than the recent advanced rendering modes, such as three-/fourdimensional ultrasound and HDlive. The contralateral side of the same structure and contralateral limbs can also be displayed. In this article, we highlight this rendering mode, focusing on its merits for the visualization of normal fetal structures as well as some congenital anomalies.
\end{abstract}

Keywords: Four-dimensional ultrasound, Fetal anomaly, Fetal development, HDlive silhouette mode, Intertwin contact, Intrapair stimulation, Twin pregnancy.

How to cite this article: AboEllail MAM, Kanenishi K, Marumo G, Masaoka H, Ejiri A, Hata T. Fetal HDlive Silhouette Mode in Clinical Practice. Donald School J Ultrasound Obstet Gynecol 2015;9(4):413-419.

Source of support: The work reported in this paper was supported by a Grant-in-Aid for Scientific Research on Innovative Areas 'Constructive Developmental Science' (No. 24119004), and a Research Grant (No. 25462561) from The Ministry of Education, Culture, Sports, Science and Technology, Japan.

\section{Conflict of interest: None}

\footnotetext{
${ }^{1}$ Research Fellow, ${ }^{2}$ Associate Professor, ${ }^{3,4}$ Director

${ }^{5}$ Segment Leader, ${ }^{6}$ Professor and Chairman

${ }^{1,2,6}$ Department of Perinatology and Gynecology, Kagawa University Graduate School of Medicine, Kagawa, Japan

${ }^{3}$ Department of Obstetrics and Gynecology, Marumo Ladies Clinic, Tokyo, Japan

${ }^{4}$ Department of Obstetrics and Gynecology, Masako Hospital Hiroshima, Japan

${ }^{5}$ Department of Ultrasound, GE Healthcare Japan Women's Healthcare Ultrasound, Tokyo, Japan

Corresponding Author: Toshiyuki Hata, Professor and Chairman, Department of Perinatology and Gynecology, Kagawa University Graduate School of Medicine, 1750-1 Ikenobe, Miki Kagawa 761-0793, Japan, Phone: +81-(0) 87-891-2174, e-mail: toshi28@med.kagawa-u.ac.jp
}

\section{INTRODUCTION}

Progress in medical technology is developing very rapidly, and numerous innovations are advancing the existing diagnostic and therapeutic tools used in this field. Ultrasound, especially in the field of perinatology, plays a big part in this technological revolution. Many rendering modes and types of software have been introduced as tools to aid in the prenatal detection of fetal anomalies. They aim at facilitating the diagnosis, increasing physicians' confidence, and achieving a better understanding of the anomalies.

GE Healthcare (Kretztechnik, Zipf, Austria) first introduced a new rendering mode (HDlive silhouette mode) in October 2014 for their new machine Voluson E10. This novel technology provides vitreous-like clarity of the fetus and placenta. ${ }^{1,2}$ Through using a shadowing effect, the outlines of structures of interest can be delineated clearly with the simultaneous display of the inner core and structure. Moreover, structures present behind this structure can also be seen. In this article, we highlight this rendering mode, focusing on its merits for the visualization of normal fetal structures as well as some congenital anomalies.

\section{NORMAL EMBRYO AND FETUS}

\section{Early Pregnancy}

The HDlive silhouette mode clearly demonstrates a normal embryo and fetus in the first trimester of pregnancy. The fetus is clearly seen surrounded by the amniotic sac with the straightforward identification of physiological midgut herniation, in addition to visualization of the umbilical cord and yolk sac (Figs 1A and B). Accurate demonstration of the spatial relationship between the embryo and surrounding structures, which can be seen fully on the same scanning plane, is no longer difficult when applying this technique.

With the advancement of pregnancy and due to different fetal positions, it is common to find that some fetal structures are hidden, such as part of the fetal head is covered by the uterine wall when displayed with the HDlive technique (Figs 2A and B). The shadowing effect of the HDlive silhouette mode enables the visualization of different fetal parts even when they are covered. Full visualization of the fetus allows the physician to completely evaluate fetal morphological development. 


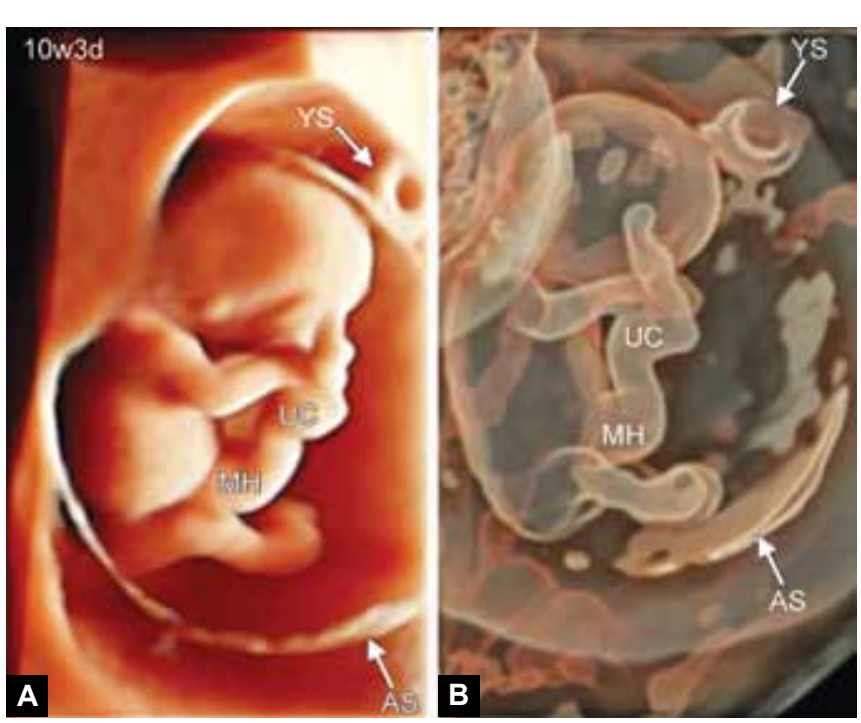

Figs $1 A$ and $B$ : A normal fetus at 10 weeks and 3 days of gestation demonstrated by HDlive (A) and the HDlive silhouette mode (B). Delineation of the outer contour is more evident using the HDlive silhouette mode, showing more fine details (AS: Amniotic sac; $\mathrm{MH}$ : Midgut herniation; UC: Umbilical cord; YS: Yolk sac)

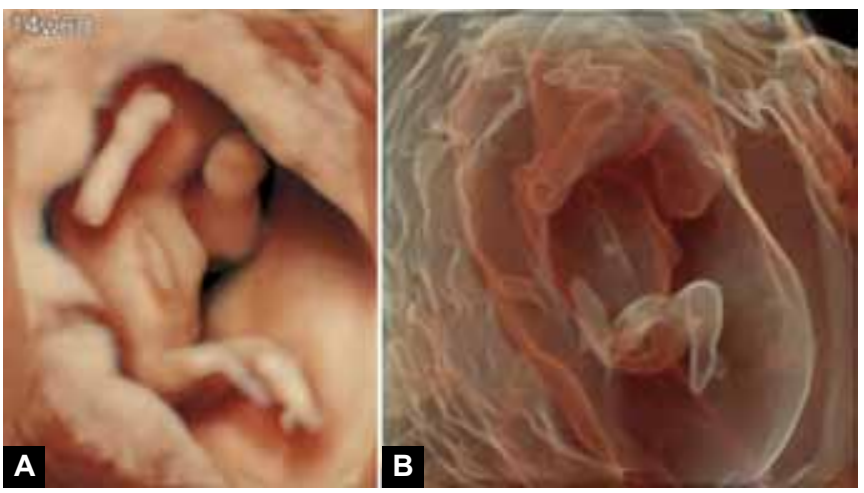

Figs 2A and B: HDlive $(A)$ and HDlive silhouette mode (B) reconstructions of a normal pregnancy at 14 weeks and 6 days of gestation. Note that the upper part of the fetal head is covered by the uterine wall and invisible on using HDlive; however, it can be clearly demonstrated when using the HDlive silhouette mode

Fetal motor activity might represent early neurological development. ${ }^{3}$ This requires the assessment of gross fetal movements, all limb movements, and fetal head movements at the same time, which necessitates a technology that enables their simultaneous display. This can only be achieved with the HDlive silhouette mode. Moreover, limb movements including those of the contralateral limbs, which usually need a different plane to be demonstrated, can be judged at the same time as ipsilateral ones (Figs $3 \mathrm{~A}$ and B). This is essential during the evaluation of fetal behavior in early pregnancy. ${ }^{4}$

\section{Intracranial Structures}

The delineation of the outer contour of different fetal organs and structures is the main merit of this technique. This becomes very useful when the skull and intracranial structures are the target of examination. The bony skull is demarcated from the outside while intracranial structures, such as the lateral ventricles, can be evaluated based on life-like images (Fig. 4). The anterior fontanelle, which remains open until about the middle of the second year, can be easily identified by its characteristic lozenge shape in addition to the demonstration of the interior of the skull through this opening using the HDlive silhouette mode (Figs 5A and B).

\section{Intra-abdominal Organs}

Spatial relationships among fetal organs and their locations can be precisely determined using the HDlive silhouette mode. The positions in relation to anatomical landmarks, such as the spine, aorta and diaphragm, which can be depicted by this technique, can also be identified. The heart location in the thorax above the level of the observable diaphragm, with the stomach on the same side but below the diaphragm, is shown (Figs 5 and 6). A diaphragmatic hernia can be easily excluded through this approach.

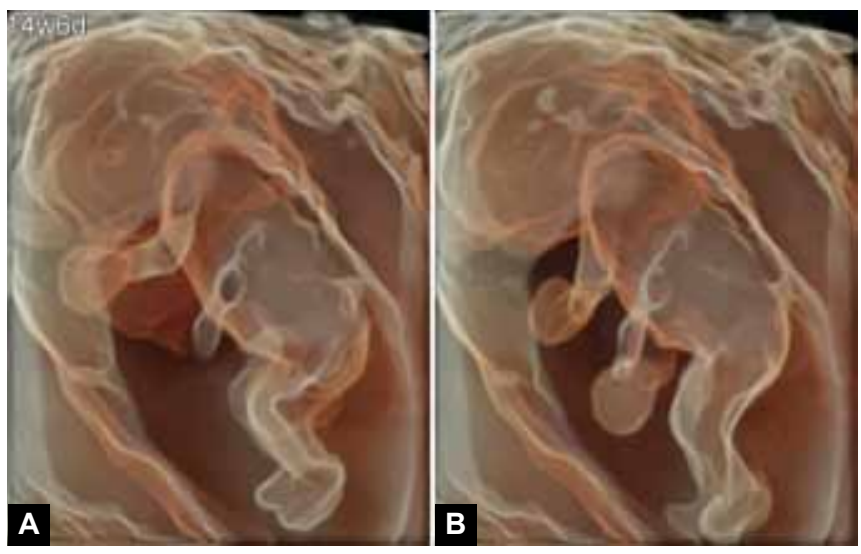

Figs $3 A$ and $B$ : Consecutive HDlive silhouette mode observation of fetal movements at 14 weeks and 6 days of gestation (A and $B$ ). Full assessment of fetal movements including the head, which lies behind the uterine wall, is achieved by the HDlive silhouette mode. The change in arm movement is clear when comparing $(A)$ to $(B)$. Note the ability to see the contralateral arm using this technique

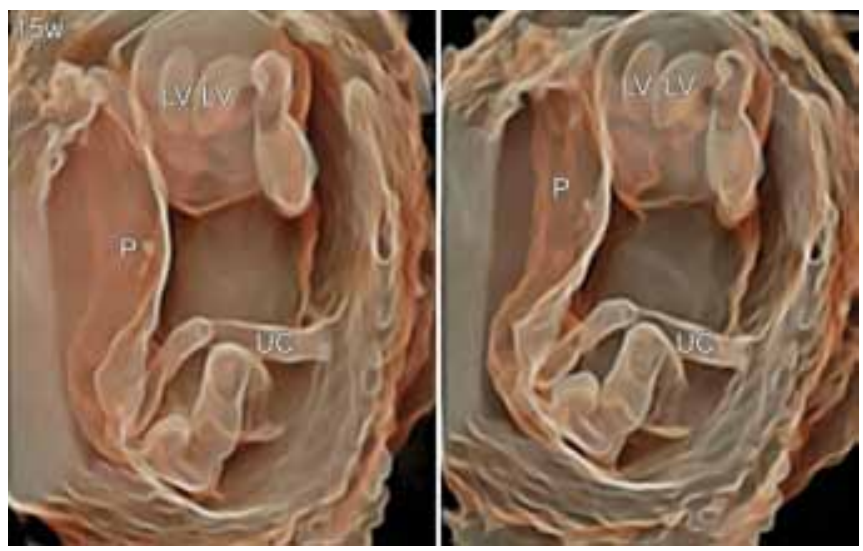

Fig. 4: The HDlive silhouette mode of a normal fetus at 15 weeks of gestation, clearly showing the lateral ventricles (LV). Spatial relationships among the fetus, umbilical cord (UC) and placenta $(\mathrm{P})$ are evident 


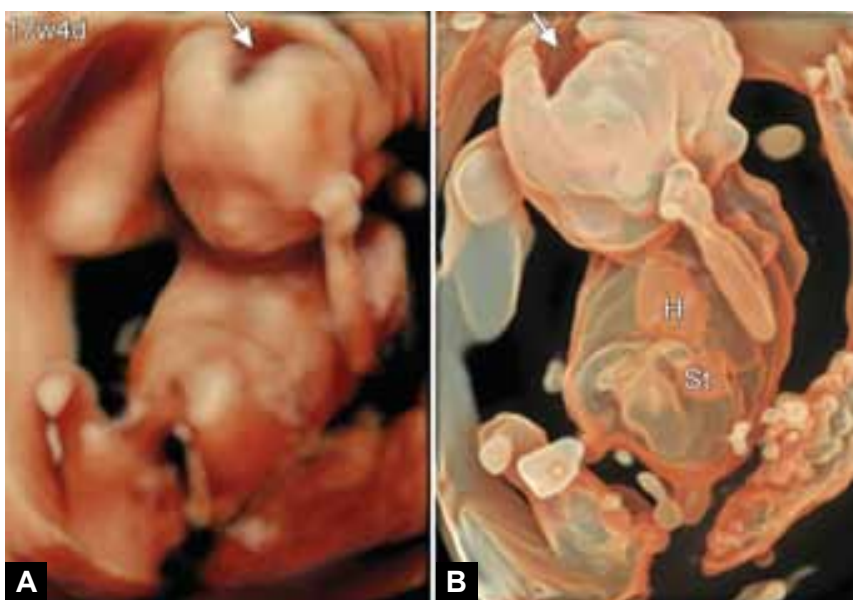

Figs 5A and B: A normal pregnancy at 17 weeks and 4 days of gestation demonstrated by HDlive $(A)$ and the HDlive silhouette mode (B). The HDlive silhouette mode is superior as it displays the anterior fontanelle (arrow), shown by HDlive, but it also depicts internal organs represented by the heart $(\mathrm{H})$ and stomach $(\mathrm{St})$

Assessment of fetal gastrointestinal tract (GIT) is difficult during fetal ultrasound due to the complex spatial relationships among its different parts. A recently published meta-analysis showed a lack of prenatal diagnostic accuracy regarding the localization of nonduodenal small intestinal atresia in addition to the difficulty in large intestinal lesion localization. ${ }^{5}$ The HDlive silhouette mode has the ability to show its detailed appearance. The fundus, body, and pylorus of the stomach can be clearly depicted (Fig. 7). A ventral panoramic view of the fetal GIT can also be obtained, similar to the actual anatomical view obtained during surgical exploration. The ascending, transverse and descending colon in addition to hepatic and splenic flexures and stomach can be displayed simultaneously, making the identification and localization of any GIT anomaly straightforward (Figs $8 \mathrm{~A}$ and $\mathrm{B}$ ). This view is identical to the one encountered during laparotomy, meaning that these images provide a life-like view of the fetal abdomen.

\section{Limbs and Skeletal System}

The shadowing effect used in this technique is also applied to the limbs to obtain a clear image for the identification of limb bones. The advantage of the HDlive silhouette mode is its ability to display the limbs as well as bones at the same time (Figs 9A and B) giving it superiority over HDlive which was previously used by Hata et $\mathrm{al}^{6}$ to diagnose skeletal anomalies. The clear demonstration of the position of different parts of fetal upper and lower limbs with clear identification of the bones forming them might represent a new and promising application of this technique.

\section{External Genitalia}

The curiosity of parents about the sex of their fetus is met daily during an obstetrician's work. Accurate diagnosis is

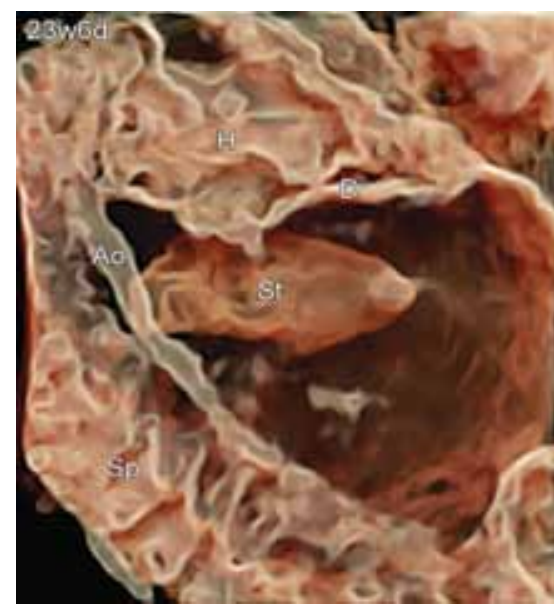

Fig. 6: The HDlive silhouette mode of a normal pregnancy at 23 weeks and 6 days of gestation. The diaphragm (D) is clearly shown with straightforward identification of the heart $(\mathrm{H})$ above it and stomach (St) below this level. The abdominal aorta (Ao) and spine (Sp) as anatomical landmarks are also displayed in the same plane

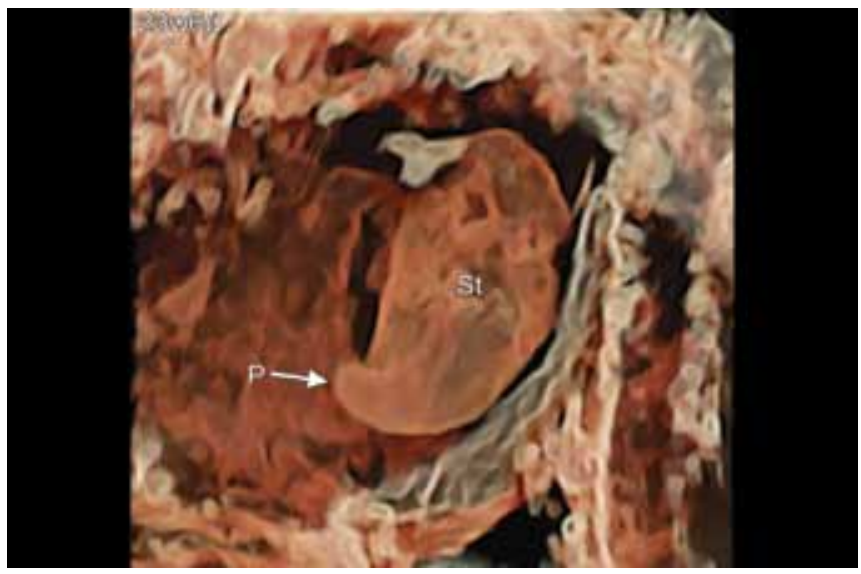

Fig. 7: A normal fetal stomach (St) shown using the HDlive silhouette mode at 23 weeks and 6 days of gestation. The arrow points to the pylorus $(P)$, which can be clearly identified as well as the body and fundus of the stomach. Spatial relationships with the visualized spine can be understood

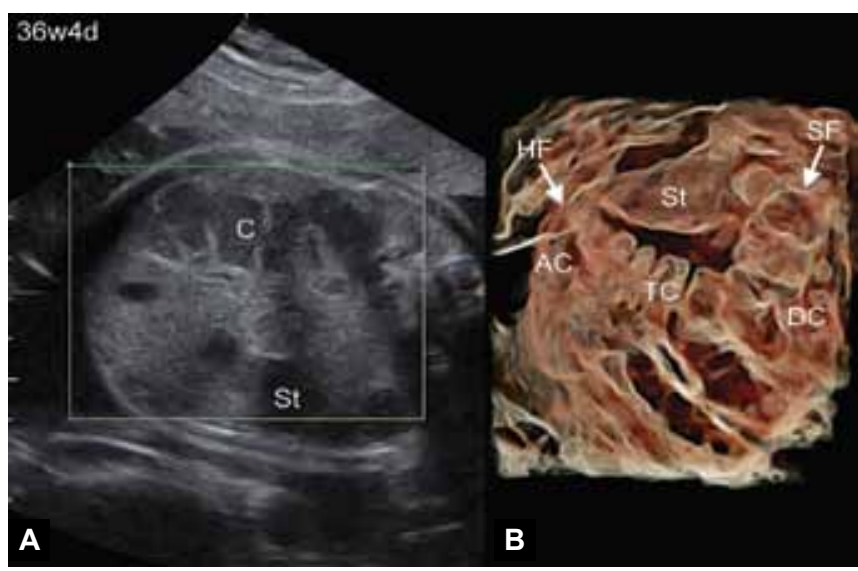

Figs 8A and B: A ventral panoramic view of the normal fetal abdomen at 36 weeks and 4 days of gestation, displayed by two-dimensional sonography $(\mathrm{A})$ and the HDlive silhouette mode (B). The spatial relationship between the stomach (St) and colon (C) with its different parts can be seen. The display of the ascending colon (AC), hepatic flexure (HF), transverse colon (TC), splenic flexure (SF), and descending colon (DC) in this order by the HDlive silhouette mode is identical to actual observation of the anatomy 


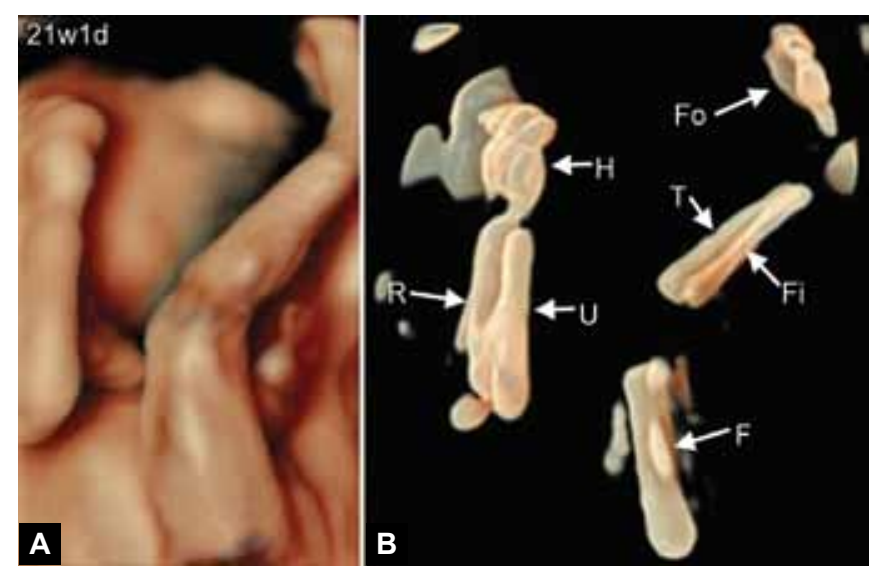

Figs 9A and B: HDlive (A) and the HDlive silhouette mode (B) images of a normal pregnancy at 21 weeks and 1 day of gestation. HDlive shows the soft tissue of the fetal limbs. The HDlive silhouette mode has the ability to demonstrate limb bones clearly and the spatial relationships among them (F: Femur; Fi: Fibula; Fo: Foot; H: Hand; R: Radius; T: Tibia; U: Ulna)

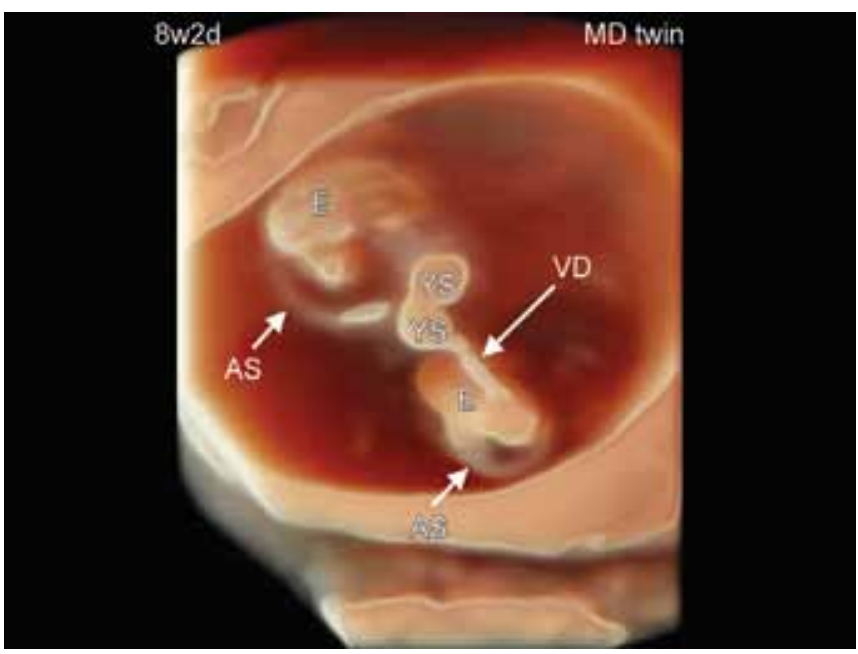

Fig. 11: The HDlive silhouette mode of monochorionic diamniotic (MD) twins at 8 weeks and 2 days of gestation. Two embryos (E), two amniotic sacs (AS), and two yolk sacs (YS) in one gestational sac can be identified. The vitelline duct (VD) connecting the lower embryo to the yolk sac can be seen

critical not only for sex determination but also to exclude genital anomalies, such as ambiguous genitalia and pseudohermaphroditism. Classic confirmation of the sex depends upon the shape of the external genitalia. ${ }^{7}$ The HDlive silhouette mode provides a clear demonstration of the external genitalia in addition to its ability to identify the presence of the testicles, confirming their descent into the scrotum (Figs 10A and B), which usually takes place during the 7th month of pregnancy.

\section{TWIN PREGNANCY}

Twin pregnancy represents one of the main dilemmas in the field of prenatal sonographic examination, as we need to confirm the diagnosis, and determine the zygocity to be able to predict the course and possible complications

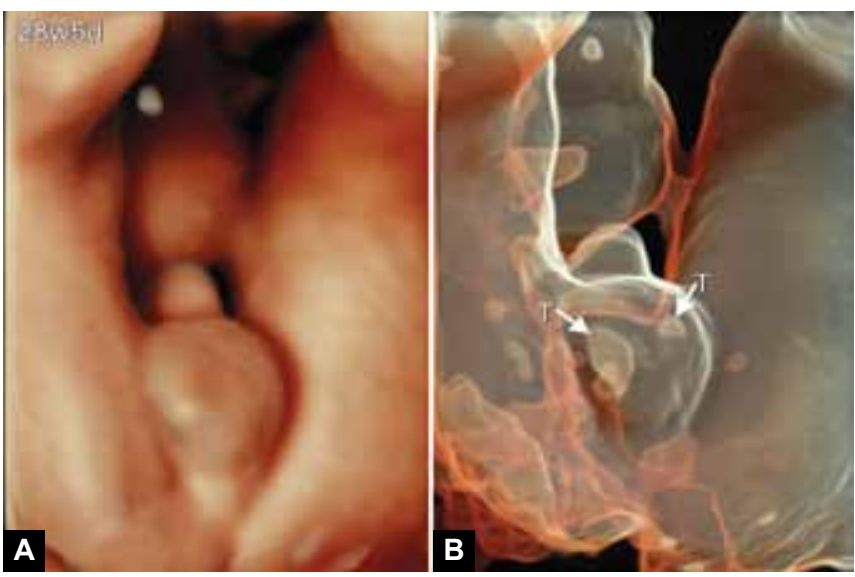

Figs $10 \mathrm{~A}$ and $\mathrm{B}$ : Fetal male external genitalia at 28 weeks and 5 days of gestation shown by HDlive (A) and the HDlive silhouette mode (B). Both techniques show the penis and scrotum, but the HDlive silhouette mode can detect the presence of the testis $(T)$

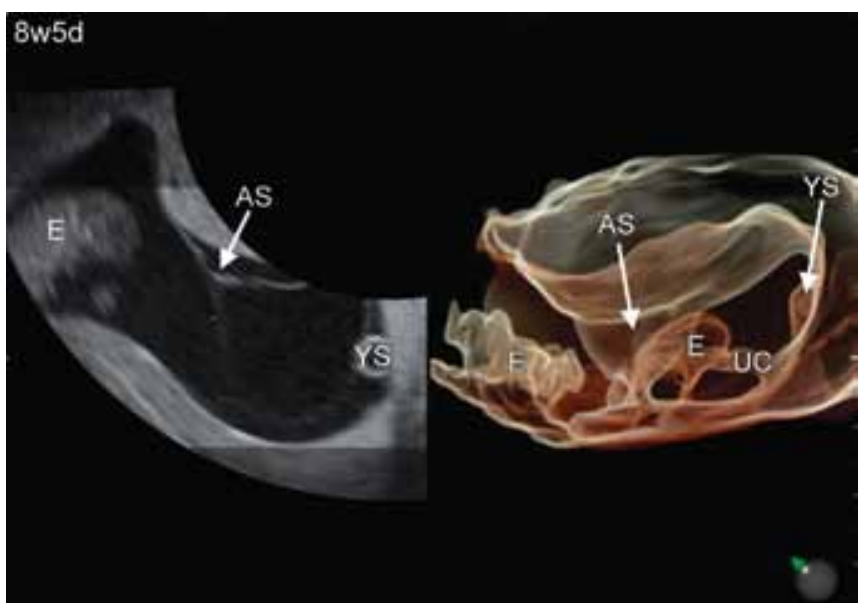

Fig. 12: Monochorionic diamniotic twin pregnancy at 8 weeks and 5 days of gestation displayed by two-dimensional sonography (right) and the HDlive silhouette mode (left). With 2D sonography, only one embryo (E) can be seen. The HDlive silhouette mode shows the presence of the other embryo. More details including the umbilical cord (UC), and clear demonstration of the amniotic sac (AS) and yolk sac (YS) are achieved

associated with it, in addition to an anatomical survey and fetal growth assessment.

The use of the HDlive silhouette mode can be a very useful tool due to its ability to show fine details of twin pregnancy very early on in gestation. In monochorionic diamniotic (MD) twins, one gestational sac can be clearly seen containing the two embryos, two yolk sacs, and two amniotic sacs. Moreover, visualization of the vitelline duct connecting the yolk sac can be achieved as at early as 8 weeks of gestation (Figs 11 and 12).

The presence of the two fetuses in one gestational sac in cases of MD twins leads to contact between them which appears in the form of touch or stimulation from one twin followed by responses from the co-twin, first described by Hata et $\mathrm{al}^{8}$ as a predictor of neurobehavioral 

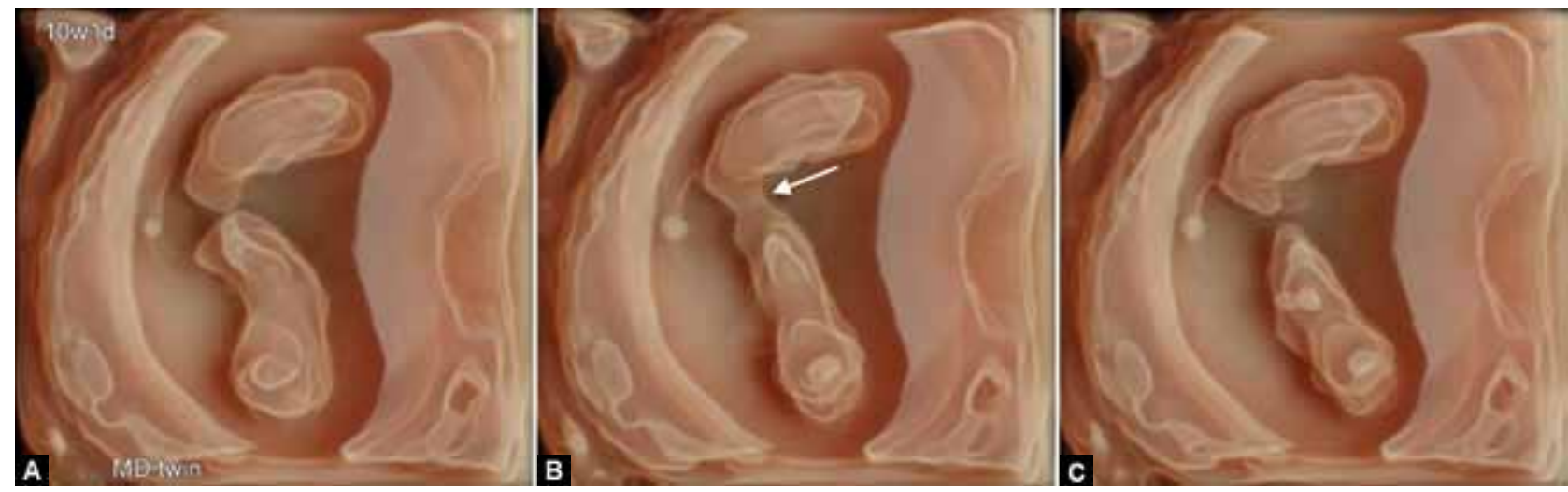

Figs 13A to C: Consecutive HDlive silhouette mode observation of leg-to-leg contact (arrow) in monochorionic-diamniotic twins

development and twin temperament and as a stimulus of tactile sensation in twins using three- (3D)/fourdimensional (4D) ultrasound. In this field, the use of the HDlive silhouette mode allows the observation of various types of intertwin contact (Figs 13 to 15 ) as early as at 8 weeks of gestation due to its ability to demonstrate fetal limbs very early on in gestation, which might not be easily identified and judged using other rendering modes.

In cases of dichorionic diamniotic twins, the dividing membrane is clearly seen. The second twin, who is hidden by the dividing membrane on an HDlive image, can be clearly identified using the HDlive silhouette mode

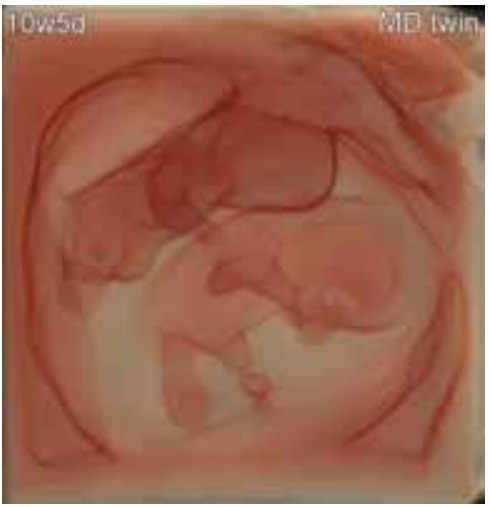

Fig. 14: Typical arm-to-trunk contact in monochorionic diamniotic twins at 10 weeks and 5 days of gestation

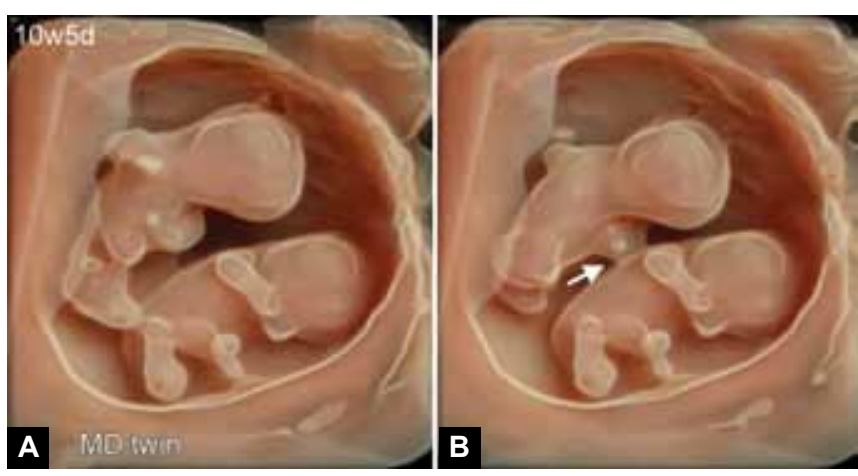

Figs 15A and B: Two successive HDlive silhouette mode images showing arm-to-trunk contact (arrow) in monochorionic-diamniotic twins at 10 weeks and 5 days of gestation (A and $B$ )

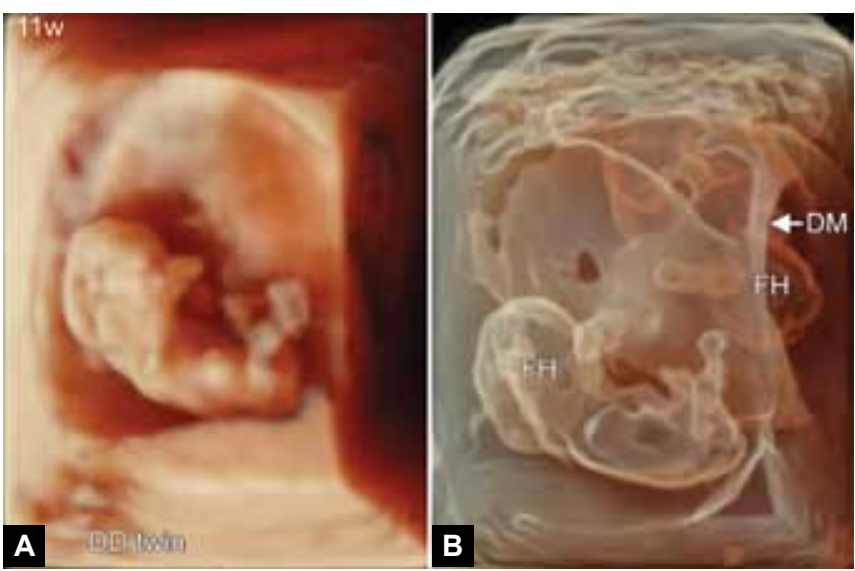

Figs 16A and B: Dichorionic diamniotic (DD) twin pregnancy at 11 weeks of gestation demonstrated by HDlive (A) and the HDlive silhouette mode (B). Only one fetus can be visualized by HDlive, while the HDlive silhouette mode demonstrates the co-twin, whose head $(\mathrm{FH})$ was present behind the other one. The dividing membrane (DM) can also be identified clearly using the HDlive silhouette mode

(Figs 16A and B). So, the HDlive silhouette mode resembles holographic technology. ${ }^{1}$

\section{FETAL ANOMALY}

Despite being a relatively new technique, the HDlive silhouette mode has been shown to be an effective diagnostic tool to aid in identifying various anomalies, including cardiovascular, placental and GIT abnormalities. ${ }^{1,2,9,10}$ Here, we present other examples of fetal anomalies, in which the HDlive silhouette mode should prove useful.

\section{Ventriculomegaly}

In the case of ventriculomegaly, simultaneous display of the dilated right and left lateral ventricles leads to a higher diagnostic accuracy and improved evaluation of the intracranial anomaly (Fig. 17). This plane is not easily achieved by conventional 2D sonography. 


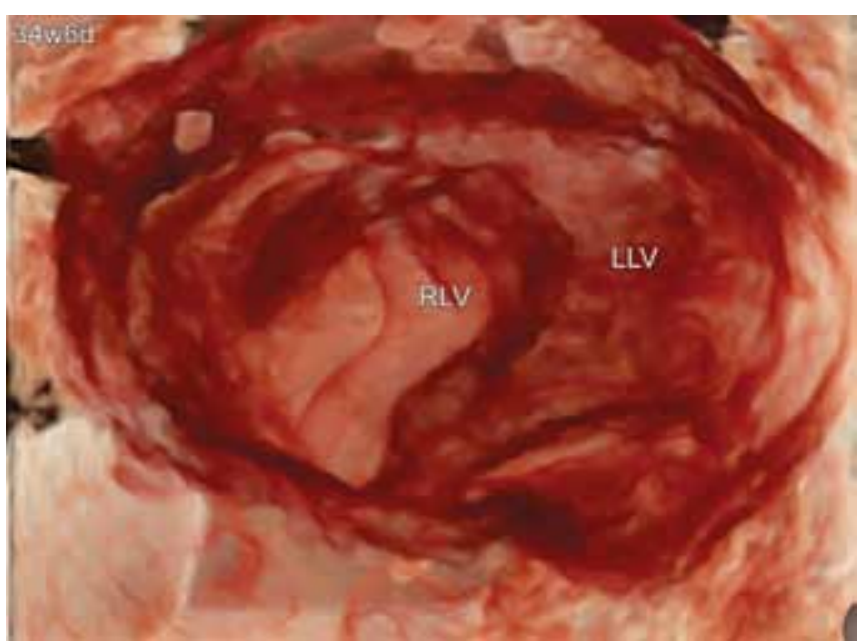

Fig. 17: The HDlive silhouette mode of dilated lateral ventricles reconstructed by the HDlive silhouette mode at 34 weeks and 6 days of gestation in a case of ventriculomegaly. Simultaneous display of the dilated right and left lateral ventricle (RLV and LLV) can be achieved

\section{Diaphragmatic Hernia}

As we mentioned earlier in this article, the HDlive silhouette mode can clearly demonstrate the diaphragm. This is very beneficial when a case of diaphragmatic hernia is evaluated using this technique, where the stomach could be visualized in the thorax located beside the heart with both of them lying above the welldemonstrated diaphragm (Fig. 18).

\section{GIT Anomalies}

In the presence of GIT anomalies, its ability to show a panoramic view of the fetal GIT makes it beneficial for complex anomalies. In jejunal stenosis, the HDlive silhouette mode depicts the presence of an atretic jejunum in addition to the dilated duodenum and stomach (Figs 19A and B). Moreover, the clearly visualized spine as anatomical landmark for the back and umbilical vein for the front provide accurate references for the orientation, which help in accurately localizing the lesion. The 2D sonographic image of this case showed a double-bubble sign, and duodenal atresia was initially suggested. Accurate evaluation of the fetal GIT from the inside as well as its outer contour, peristaltic wave, and relation with surrounding structures represent the main advantages of the use of the HDlive silhouette mode in GIT anomalies. ${ }^{10}$

The inner wall of the dilated intestinal loops with different caliber changes is clearly demonstrated in the case of meconium peritonitis (Figs 20A and B). This matches the picture of meconium peritonitis caused by meconium ileus as previously described by AboEllail et al. ${ }^{11}$ Two-dimensional sonography alone is not sufficient for the accurate prenatal diagnosis of these cases.

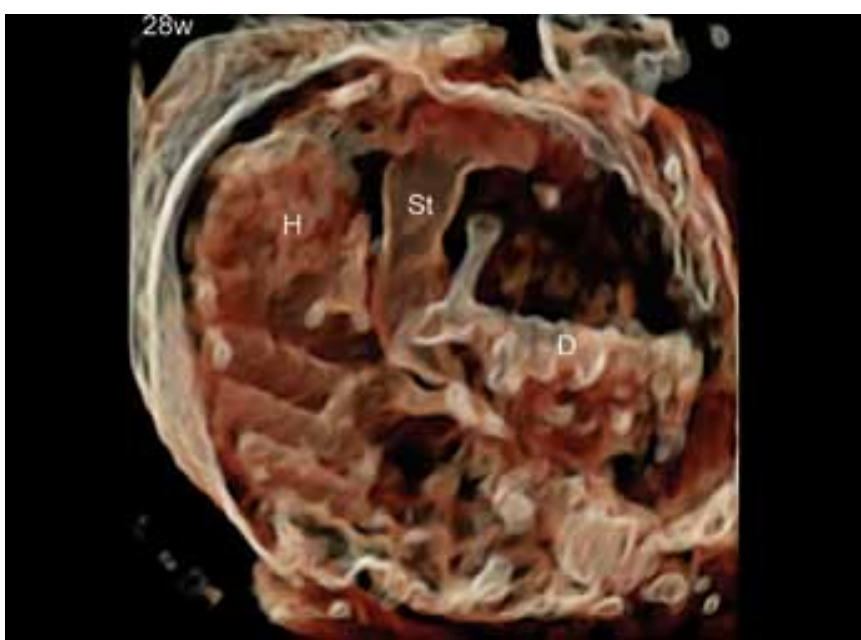

Fig. 18: The HDlive silhouette mode in a case of diaphragmatic hernia at 28 weeks of gestation. The herniated stomach (St) can be seen beside the heart $(\mathrm{H})$ in the chest above the level of the clearly visualized diaphragm (D)
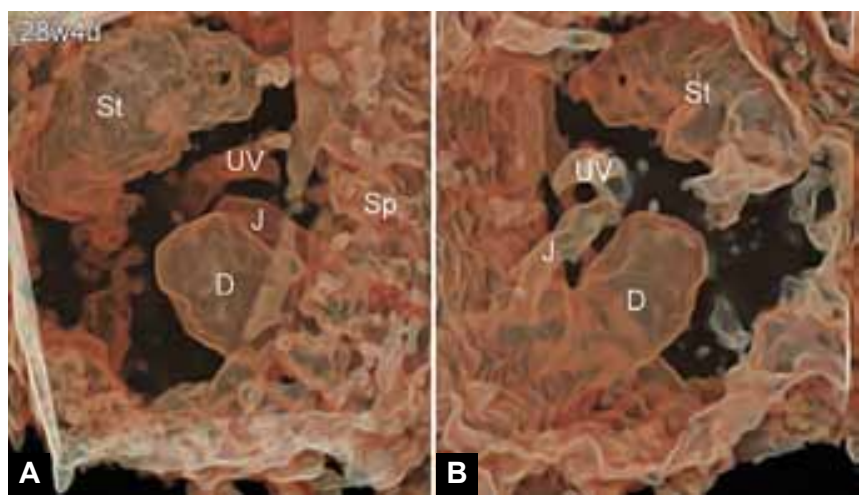

Figs 19A and B: The HDlive silhouette mode of jejunal stenosis at 28 weeks and 4 days of gestation, showing the dilated stomach (St). The dilated duodenum (D), with the jejunum (J) lying behind it, can be seen. Spatial relationships among these structures as well as the clearly visualized surrounding landmarks, the spine (Sp) from the back and umbilical vein from the front, can be identified with an oblique view from the left $(A)$ and right $(B)$ sides

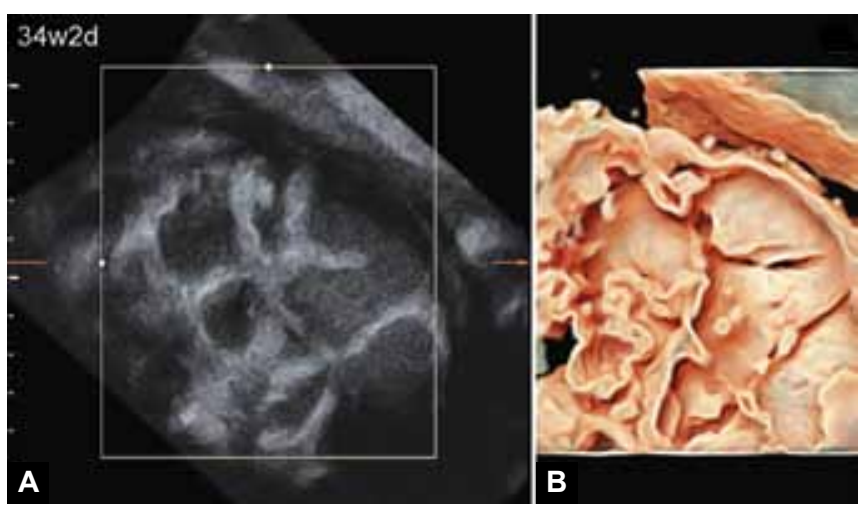

Figs 20A and B: Two-dimensional $(A)$ and HDlive silhouette mode (B) images of meconium peritonitis at 34 weeks and 2 days of gestation. The dilated intestinal loops with different calibers and meconium inside them can be identified. Both the outer contour and inner lumen of intestinal loops are displayed particularly using the HDlive silhouette mode 


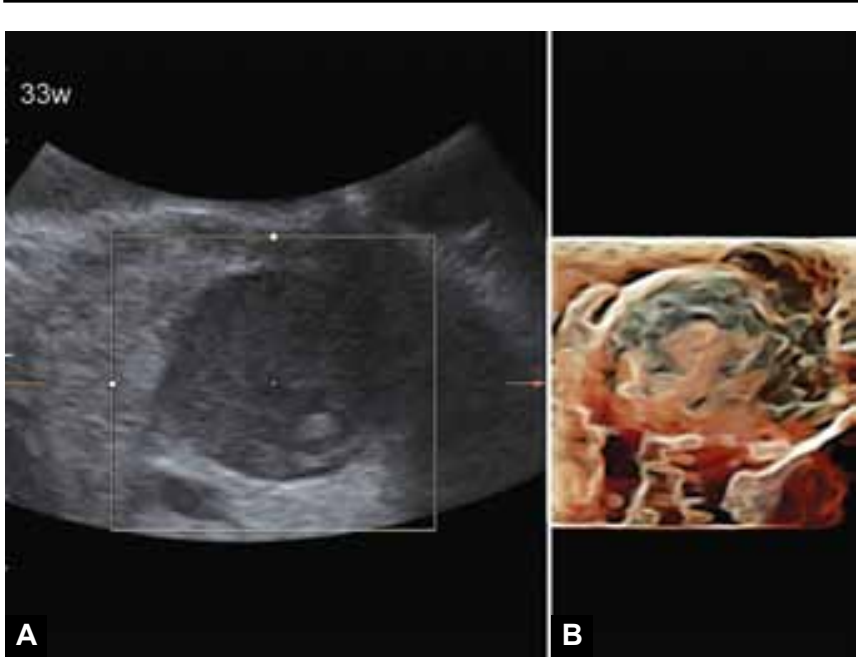

Figs 21A and B: Two-dimensional (A) and HDlive silhouette mode (B) images of an enteric duplication cyst at 33 weeks of gestation. The characteristic thick double wall and presence of debris inside are evident using the HDlive silhouette mode

The combined abilities of delineating the outlines and showing the core was very advantageous in an case of enteric duplication cyst (Figs 21A and B). The thick double wall, which is key in the diagnosis of an enteric duplication cyst, could be obtained clearly using the HDlive silhouette mode. Moreover, the inner structure showed opacities representing the debris inside it. This is beneficial in differentiating it from other cystic lesions located in the fetal abdomen.

\section{CONCLUSION}

The HDlive silhouette mode may provide new insights into normal fetal structures in early pregnancy and different congenital malformations. Its unique character of displaying the outlines of structures of interest while simultaneously showing the inner core makes it more beneficial in identifying a normal anatomy and diagnosing complex congenital malformations. Moreover, the shadowing effect to demonstrate structures present behind the directly visualized structure makes it more advantageous than recent advanced rendering modes, such as $3 \mathrm{D} / 4 \mathrm{D}$ ultrasound and HDlive. The contralateral side of the same structure and contralateral limbs can be displayed in the same way, facilitating comprehensive judgment during HDlive silhouette mode examinations.

In twin pregnancy, the simultaneous display of both twins and their sacs and even the contact between them, allows not only an accurate description of the pregnancy but also the chance to evaluate intertwin contacts and, therefore, the evaluation of their neurobehavioral development can be easily achieved.

As with any other new rendering mode, all depends on favorable quality and an appropriate plane during 2D acquisition of the image. Full familiarity of the sonographer with the normal anatomy and an awareness of congenital anomalies will also facilitate the rapid learning of skills required for this technique.

\section{REFERENCES}

1. AboEllail MAM, Hanaoka U, Numoto A, Hata T. HDlive image of fetal giant hemangioma. J Ultrasound Med 2015; 34(12):2315-2318.

2. AboEllail MAM, Kanenishi K, Tenkumo C, Mori N, Katayama T, Koyano K, Kusaka T, Hata T. 4D power Doppler with HDlive silhouette mode in antenatal diagnosis of right aortic arch with aberrant left subclavian artery. J Ultrasound Med 2015. In press.

3. Stanojevic M, Kurjak A, Salihagić-Kadić A, Vasilj O, Miskovic B, Shaddad AN, Ahmed B, Tomasovic S. Neurobehavioral continuity from fetus to neonate. J Perinat Med 2011;39(2):171-177.

4. Hata T, Kanenishi K, Tnaka H, Marumo G, Sasaki M. Four dimensional ultrasound evaluation of fetal neurobehavioral development. Donald School J Ultrasound Obstet Gynecol 2010;4(3):233-248.

5. Virgone C, D'Antonio F, Khalil A, John R, Manzoli L, Giuliani S. Accuracy of prenatal ultrasound in detecting jejunal and ileal atresia: systematic review and meta-analysis. Ultrasound Obstet Gynecol 2015;45(5):523-529.

6. Hata T, Hanaoka U, Tenkumo C, Sato M, Tanaka H, Ishimura $\mathrm{M}$. Three- and four-dimensional HDlive rendering images of normal and abnormal fetuses: pictorial essay. Arch Gynecol Obstet 2012;286(6):1431-1435.

7. Odeh M, Grinin V, Kais M, Ophir E, Bornstein J. Sonographic fetal sex determination. Obstet Gynecol Surv 2009;64(1): 50-57.

8. Hata T, Aoki S, Miyazaki K, Iwanarai O, Sawada K, Tagashihara T. Three-dimensional ultrasonographic visualization of multiple pregnancy. Gynecol Obstet Invest 1998;46 (1):26-30.

9. AboEllail MAM, Kanenishi K, Mori N, Kurobe A, Hata T. HDlive image of circumvallate placenta. Ultrasound Obstet Gynecol 2015;46(4):513-514.

10. AboEllail MAM, Tanaka H, Mori N, Hanaoka U, Hata T. HDlive silhouette mode in antenatal diagnosis of jejunal atresia. Ultrasound Obstet Gynecol 2015 Sep 4. DOI: 10.1002/ uog.15737 [Epub ahead of print].

11. AboEllail MAM, Tanaka H, Mori N, Tanaka A, Kubo H, Shimono R, Hata T. HDlive imaging of meconium peritonitis. Ultrasound Obstet Gynecol 2015;45(4):494-496. 